\title{
Evaluation of the Survivability of SARS-CoV-2 on Cardboard and Plastic Surfaces and the Transferability of Virus from Surface to Skin
}

\author{
Giffe T. Johnson ${ }^{*}$, Craig Loehle ${ }^{1}$, Sifang S. Zhou ${ }^{2}$, Cory Chiossone², \\ James Palumbo' ${ }^{\text {, Paul Wiegand }}{ }^{1}$ \\ ${ }^{1}$ National Council for Air and Stream Improvement (NCASI), Cary, USA \\ ${ }^{2}$ Microbac Laboratories, Inc., Sterling, USA \\ Email: ^gjohnson@ncasi.org
}

How to cite this paper: Johnson, G.T., Loehle, C., Zhou, S.S., Chiossone, C., Palumbo, J. and Wiegand, P. (2021) Evaluation of the Survivability of SARS-CoV-2 on Cardboard and Plastic Surfaces and the Transferability of Virus from Surface to Skin. Occupational Diseases and Environmental Medicine, 9, 63-73.

https://doi.org/10.4236/odem.2021.92006

Received: April 21, 2021

Accepted: May 23, 2021

Published: May 26, 2021

Copyright $\odot 2021$ by author(s) and Scientific Research Publishing Inc. This work is licensed under the Creative Commons Attribution International License (CC BY 4.0).

http://creativecommons.org/licenses/by/4.0/

(c) (i) Open Access

\begin{abstract}
Objective: To 1) characterize the decay curve of infective SARS-CoV-2 over time on the surface of cardboard packaging and plastic mailer packaging; 2) characterize the transferability over time of virus-inoculated cardboard packaging and plastic mailer packaging to skin. Methods: We inoculated samples of plastic and cardboard packaging with a titer of SARS-CoV-2 $>10^{6} \mathrm{TCID}_{50} /$ $\mathrm{mL}$ to evaluate the survivability and transferability to the skin (pig skin) over time. A cell culture-based infectivity assay $\left(\mathrm{TCID}_{50}\right)$ was used to determine viral titers. Regression analysis was used to characterize decay curves. Results: The time that SARS-CoV-2 remained transferable to skin was reduced on both packaging substrates compared to the total time of survivability, though cardboard demonstrated a substantially larger reduction. Virus inoculated plastic substrates continued to transfer the virus to the skin after 7 hours of holding time and regression analysis predicts this transferability would remain detectable up to 9.5 hours of holding time. Inoculated cardboard substrates demonstrated detectable transfer at 15 minutes of holding time, but no viable virus could be detected on the skin after 30 minutes of holding time. Conclusions: The type of material used as a packaging substrate substantially modifies the potential for SARS-CoV-2 fomite transmission. The use of materials that limit fomite transmission from packaging should be considered among strategies to reduce the transmission of SARS-CoV-2. Future research should investigate the generalizability of these findings for other viral pathogens that potentially transmit via fomite.
\end{abstract}

\section{Keywords}

SARS-CoV-2, Fomite, Cardboard, Plastic, Viral Transmission to Skin 


\section{Introduction}

The SARS-CoV-2, novel human coronavirus was erupted in Wuhan, Hubei Province, China in December 2019 [1]. Certain types of human coronaviruses produce respiratory illnesses Severe Acute Respiratory Syndrome (SARS) and Middle East Respiratory Syndrome (MERS) [2]. SARS-CoV-2 produces the respiratory illness known as COVID-19. Reported COVID-19 illnesses have ranged from mild to severe, including respiratory illness resulting in death. Severe cases are most common in those in high-risk groups, including older people and people of all ages with severe chronic medical conditions including (but not limited to) heart disease, lung disease, and diabetes [3].

The Centers for Disease Control and Prevention (CDC) indicates that surface disinfection is part of the exposure control strategy to limit the spread of COVID19. Contact transmission is an infection spread through direct contact with an infectious person (e.g., touching during a handshake) or with an article or surface that has become contaminated, referred to as fomite transmission [4].

Given the potential fomite exposure pathway for the SARS-CoV-2 virus, there is interest in determining the survivability of the virus on various substrates to characterize those with have greater or lesser potential to be a source of exposure, though little data has been generated to address this issue. van Doremalen et al. (2020) evaluated the residency time of SARS-CoV-2 on several materials and substrates and reported that viable virus could be detected in aerosols up to 3 hours post aerosolization, up to 4 hours on copper, up to 24 hours on cardboard, and up to 2 - 3 days on plastic and stainless steel [5]. Chin et al. (2020) reported that no infectious virus could be recovered from printing and tissue papers after 3-hour incubation [6]. Consistent with the findings of van Doremalen et al. (2020), Chin et al. (2020) reported that residency times were typically longer on smooth, non-porous surfaces [5] [6].

Packaging materials received at home, businesses, or healthcare facilities are of special interest for SARS-CoV-2 as it allows an exposure pathway even for those practicing standard mitigation strategies. Packages may come into contact with multiple packers and carriers before reaching their ultimate destination and may receive viral particles from any packer or carrier that is actively shedding SARS-CoV-2 virus. Several studies exist that have attempted to characterize fomite transmission of virus to skin, but these studies typically either have used a non-pathogenic virus with human hands or relied on a theoretical model to characterize the transfer of pathogenic virus to human skin in order to avoid human contact with a pathogenic virus [7] [8] [9]. No study to date has evaluated the potential for a contaminated fomite to actually transfer SARS-CoV-2 viral particles to skin from casual contact. As well, the laboratory procedure to recover virus from surfaces in current studies is extremely rigorous and is not representative of the fomite's ability to actually allow the transfer of, and potential subsequent infection by, SARS-CoV-2.6 As such, an important data gap exists regarding the potential for SARS-CoV-2 to transfer from various fomite ma- 
terials to skin.

To address these data gaps regarding the exposure pathway of the SARS-CoV-2 virus from packaging materials, the current study was designed to characterize the transferability over time from virus-inoculated cardboard packaging and plastic mailer packaging to skin.

\section{Methods}

\subsection{Materials}

The challenge virus in this study is the Severe Acute Respiratory Syndrome-Related Coronavirus 2 (SARS-CoV-2) (COVID-19 Virus), Strain: USA-WA1/2020, Source: BEI Resources (Manassas, VA, USA), NR-52281. The host cell line used for titer measurement is Vero E6, ATCC CRL-1586 (Manassas, VA, USA). Substrate materials consisted of cardboard (comprised of $23 \#$ medium sandwiched between two 26\# linerboard sheets) samples (each cut to $\sim 2 " \times 2$ ") and plastic (polyethylene) mailer samples (each cut to $\sim 2 " \times 2 "$ ). The human skin simulant used was Stellen Medical Porcine Skin Sheets sourced from Fisher Scientific ${ }^{\circledR}$.

\subsection{Experimental Protocol}

The material samples were not treated with chemical antivirals or antimicrobials. Each type of material was evaluated independently. For each type of material, a 2 inch $\times 2$ inch piece was cut and exposed to UV light for 15 min per side to reduce the bioburden. Each piece had $100 \mathrm{uL}$ virus spread evenly over the surface. The pieces were held under ambient conditions $\left(20^{\circ} \mathrm{C} \pm 3^{\circ} \mathrm{C}, 30 \%-70 \%\right.$ relative humidity). In the first phase of the experiment, six holding times after $\mathrm{t}$ $=0$ were tested: $1,3,7,12,16$, and 24 hours (cardboard) or 36 hours (plastic). The longer final time point for plastic (e.g. 36 hours) was selected based on previous findings in the scientific literature suggesting that plastic surfaces exhibit longer survival periods for SARS-CoV-2 compared with cardboard [5]. A starting inoculum concentration of $106.55 \mathrm{TCID}_{50} / \mathrm{mL}$ was used.

After each holding time, virus was extracted from the material surfaces and analyzed for the number of infectious viral units by a cell culture-based infectivity assay $\left(\mathrm{TCID}_{50}\right)$. Due to transferability results from carboard to skin near or below the limit of detection (LOD) at all time points in the first phase of experimentation, an additional phase of experimentation was conducted to characterize survivability and transferability at holding times less than 1 hour. The second phase of this study followed the same study protocol as the first phase, evaluating only the cardboard packaging substrate for holding times of 15 seconds, 1 minute, 3 minutes, 5 minutes, 15 minutes, and 30 minutes. A starting inoculum concentration of $106.43 \mathrm{TCID}_{50} / \mathrm{mL}$ was used in this phase of experimentation.

Concurrent with the survival experiments, independent samples were evaluated for the transferability of the virus to a human skin simulant, laboratory grade pig skin. Samples had a piece of pig skin applied to the surface at each holding time to simulate a touch and transfer action by manually pressing the 
skin against the carrier with light pressure, holding for 5 seconds, and then wiping the skin across the carrier. The virus was then recovered from the pig skin and assayed using $\mathrm{TCID}_{50}$. All experiments were performed in three replicate runs $(\mathrm{N}=3)$ per condition. For all samples, virus was recovered with $15-\mathrm{mL}$ of viral recovery media and scraped with a cell scraper. An aliquot of the extraction sample was ten-fold serially diluted in dilution medium (DM) and inoculated onto host cells to determine the viral infectious units. The 50\% tissue culture infectious dose per $\mathrm{mL}\left(\mathrm{TCID}_{50} / \mathrm{mL}\right)$ was determined using the method of SpearmanKarber [10] [11]. In the case where a sample contained no detectable virus, a statistical analysis was performed based on Poisson distribution to determine the theoretical maximum possible titer for that sample.

In parallel, an aliquot of the original viral stock was held and assayed for viral infectious units at 3 time points over the total holding period.

The residual infectious virus in the test and controls were detected by viral-induced cytopathic effect (CPE) [12]. Dilutions of the viral recovery sample were added to cultured cell monolayers in a multi-well plate at a minimum of four wells per dilution per sample. The inoculated plates were incubated at $36 \pm$ $2 \mathrm{C}$ in $5 \% \pm 3 \% \mathrm{CO}_{2}$ for $4-9$ days. The host cell cultures were observed and refed, as necessary, during the incubation period. The virus-specific CPE was scored by examining both tests and controls. The general LOD for the infectivity assay was $0.83 \log _{10} \mathrm{TCID} 50 / \mathrm{mL}$, expressed as $2.01 \log _{10} \mathrm{TCID}_{50}$ per sample (since the total volume of extraction was $15 \mathrm{~mL}$ ), and based on the Poisson distribution which is considered statistically conservative. If one assay well demonstrated positivity and one well was negative, a titer of $0.59 \log _{10} \mathrm{TCID} 50 / \mathrm{mL}$ was calculated, expressed as $1.77 \log _{10}$ TCID50 per sample, which is near the LOD. Good Laboratory Practices (GLP) was used in this study.

\subsection{Statistical Analysis}

Summary statistics were produced in the form of mean $\log _{10}$ TCID50/mL concentrations with standard error. To estimate the time at which viral inoculum decayed to the point of non-detect on surfaces, an exponential decay model was used to predict time to LOD. Log transformed viral concentration data were analyzed through linear regression to produce a point estimate of time to intersection with the LOD and $95 \%$ confidence limits.

\section{Results}

\subsection{Survivability}

Figure 1 presents the results of the mean with a standard error of 3 replicates of SARS-CoV-2 concentrations for each holding time recovered from the surface of cardboard and plastic mailer packaging substrates. These results are comparable to those reported by van Doremalen et al. (2020) in that SARS-CoV-2 was detectable, but near the limit of the detection after 24 hours of residency time on cardboard. On the plastic substrate, SARS-CoV-2 remained detectable after 24 
hours of residency but measured near the LOD after 36 hours of residency.

Regression analysis for cardboard (Figure 2) estimates the decay rate, indicating that virus inoculum is reduced to the LOD by 31.8 hours ( $95 \%$ CI 23.4 , 45.4 hours). The results of regression analysis for viral survival on plastic mailers (Figure 3) estimates 22.0 hours (95\% CI 16.2, 31.3 hours) to reach the LOD for

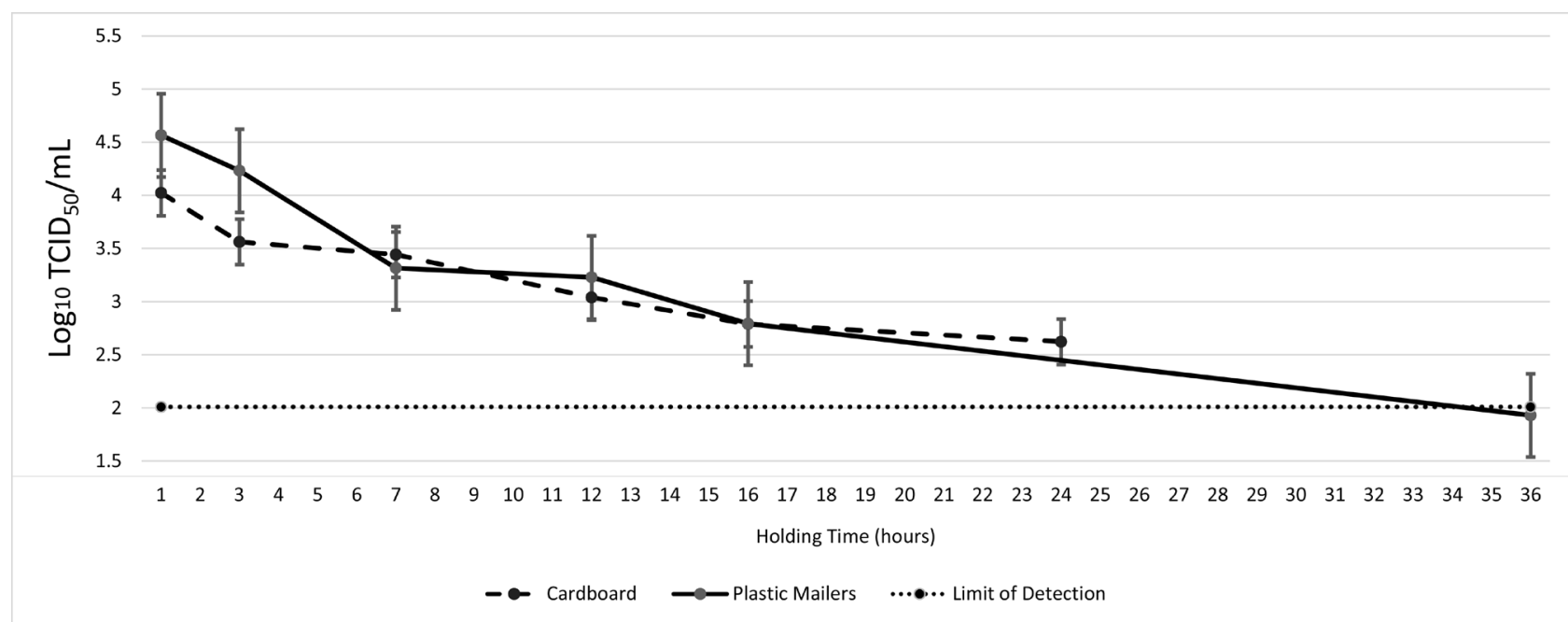

*The general LOD for the infectivity assay was $0.83 \log _{10} \mathrm{TCID}_{50} / \mathrm{mL}$, expressed as $2.01 \log _{10} \mathrm{TCID}_{50}$ per sample, and based on Poisson distribution which is considered statistically conservative. ${ }^{\mathrm{i}}$ Indicates one assay well demonstrated positivity in one replicate, resulting in a calculated titer of $0.59 \log _{10} \mathrm{TCID}_{50} / \mathrm{mL}$, expressed as $1.77 \log _{10} \mathrm{TCID}_{50}$ per sample, which is near the LOD.

Figure 1. Survivability of SARS-CoV-2 on cardboard and plastic packaging material (mean \pm standard error).

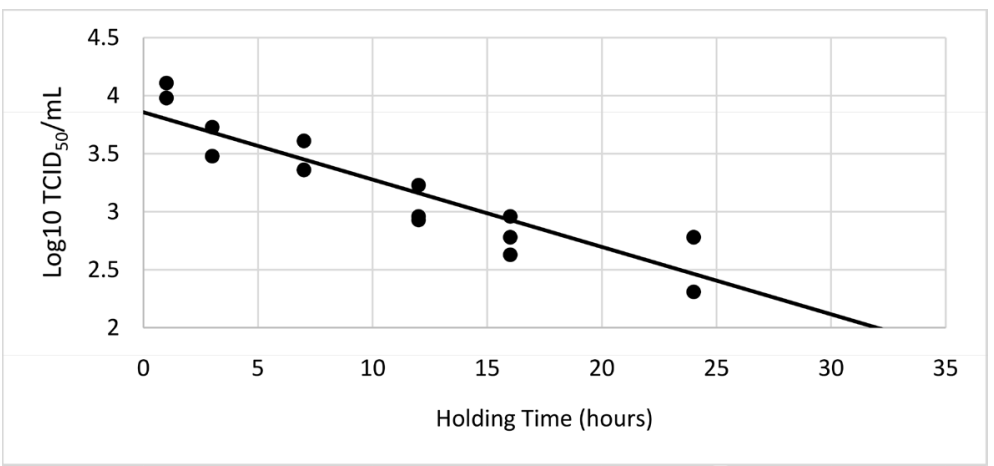

Figure 2. Linear regression of log transformed viral survival data on cardboard.

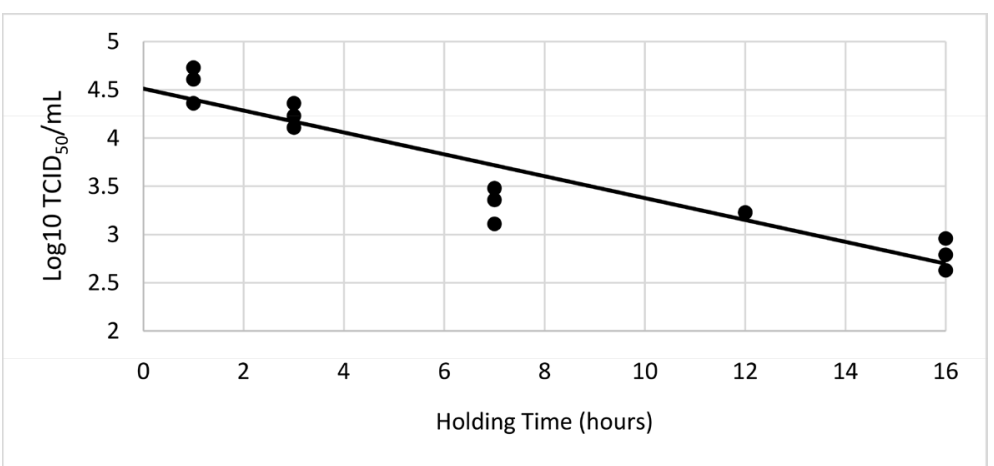

Figure 3. Linear regression of log transformed viral survival data on plastic mailers. 
the infectivity assay. Given the extensive overlap in confidence intervals calculated for the time to reach LOD for carboard and plastic mailers, we cannot conclude that there is a statistically significant difference for survivability of the virus between cardboard and plastic substrates at 95\% confidence limit.

\subsection{Transferability}

These results indicate the amount of virus that was able to transfer to pig skin from contact with an inoculated packaging substrate (Figure 4). For cardboard samples, after 1 hour of holding time (the earliest evaluated time point in phase 1) pig skin that came into contact with the inoculated cardboard material either measured trace amounts of virus near the LOD or did not receive any detectable virus from that contact. The lack of transfer of virus to pig skin was evident throughout all holding times evaluated despite clear survivability on the inoculated substrate. For holding times of 3, 12, 16, and 24 hours, no viral positivity was identified in any assay wells for any replicate, indicating that no results were above the LOD transferred to skin. At 1 hour of holding time, 1 well of 1 replicate demonstrated positivity and at 7 hours of holding time 1 well in 2 replicates demonstrated positivity resulting in estimated concentrations near the LOD transferred to skin with extremely low estimated transfer efficiencies of $0.7 \%$ and $2.6 \%$ (e.g. concentration on skin/concentration on substrate) respectively from cardboard to skin. It is important to note that concentrations and transfer efficiencies for hours 1 and 7 are calculated with multiple non-detect values assigned

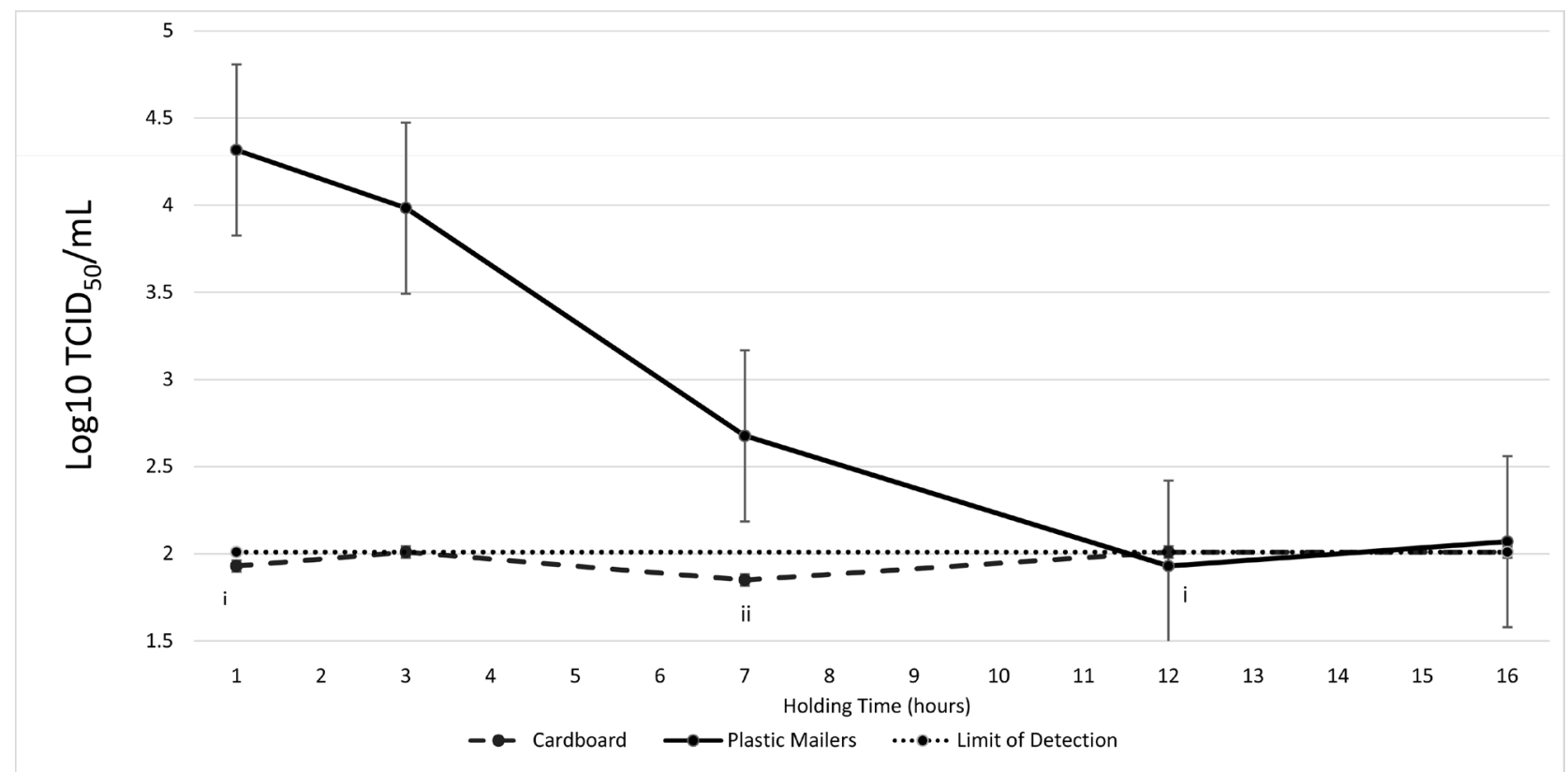

*The general LOD for the infectivity assay was $0.83 \log _{10} \mathrm{TCID}_{50} / \mathrm{mL}$, expressed as $2.01 \log _{10} \mathrm{TCID}_{50}$ per sample, based on Poisson distribution which is considered statistically conservative. ${ }^{\mathrm{i}}$ Indicates one assay well demonstrated positivity in one replicate, resulting in a calculated titer of

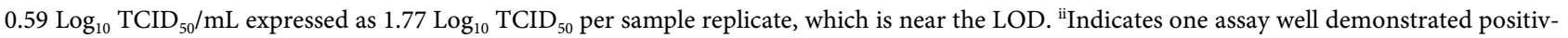
ity in two replicates, resulting in a calculated titer of $0.59 \log _{10} \mathrm{TCID}_{50} / \mathrm{mL}$ expressed as $1.77 \log _{10} \mathrm{TCID}_{50}$ per sample replicate, which is near the LOD.

Figure 4. SARS-CoV-2 recovered from skin after contact with cardboard and plastic packaging (mean \pm standard error). 
as the LOD and likely overestimate any potential transfer.

Plastic mailers, however, transferred viable virus to pig skin at least 7 hours after the plastic was inoculated. As well, the transfer of virus from plastic to skin is highly efficient. At the 1 hour and 3 hour holding times, the transfer efficiency of the virus to skin was $56 \%$. At 7 hours the transfer efficiency was $23 \%$. The regression analysis for the transferability of virus from the inoculated plastic substrate (Figure 5) estimates that viral transfer will continue to be detectable from plastic to skin until 9.5 (95\% CI 6.2, 15.9) hours post inoculation. As the virus was not detected on any pig skin samples above trace amounts that came into contact with inoculated cardboard samples, no regression analysis could be conducted for these samples.

\subsection{Phase 2 Results}

In phase 2, survivability of the SARS-CoV-2 virus on cardboard remained fairly stable with slight decay over 30 minutes measuring $4.44 \log _{10} \mathrm{TCID}_{50}$ per sample at 15 seconds and $4.02 \log _{10} \mathrm{TCID}_{50}$ per sample at 30 minutes (Figure 6). Regression analysis estimates 2.01 hours $(95 \%$ CI $1.38,15.66)$ for viral concentrations to reach the LOD on cardboard. However, due to the heavily biased sample times in the early timeframe (before 15 minutes) and the large width of the confidence interval, this regression-based estimate is not considered reliable.

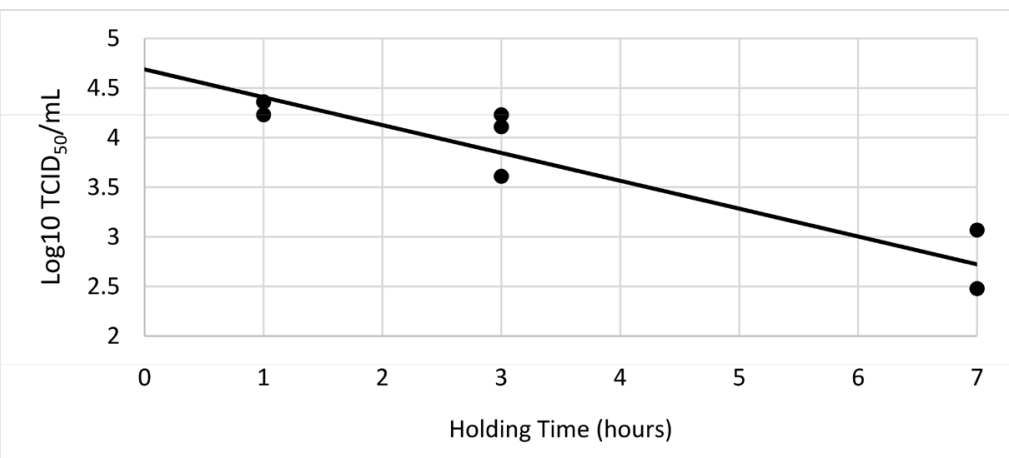

Figure 5. Linear regression of log transformed viral transfer to pig skin from plastic mailers.

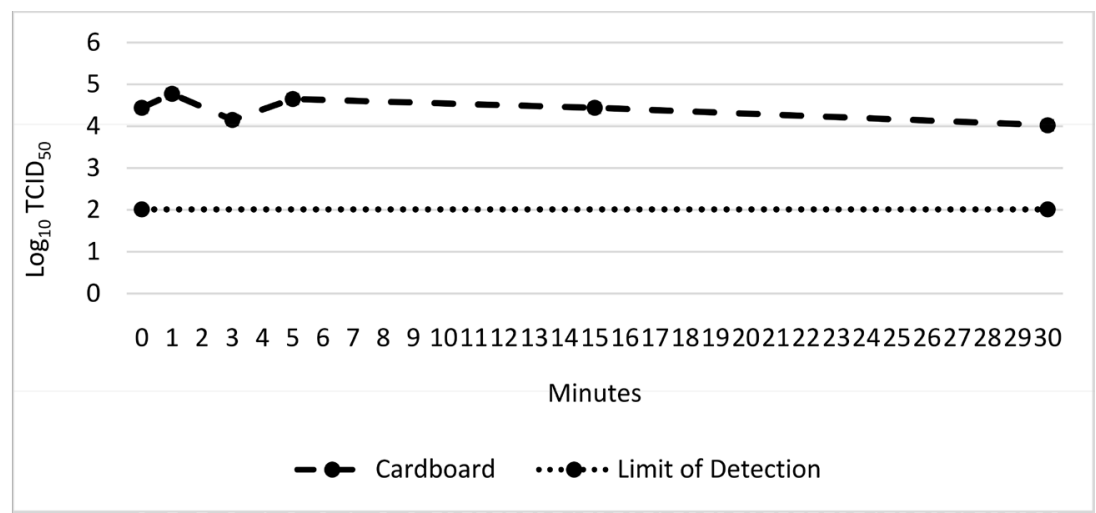

Figure 6. Survivability of SARS-CoV-2 on cardboard over 30 minutes (mean \pm standard error). 


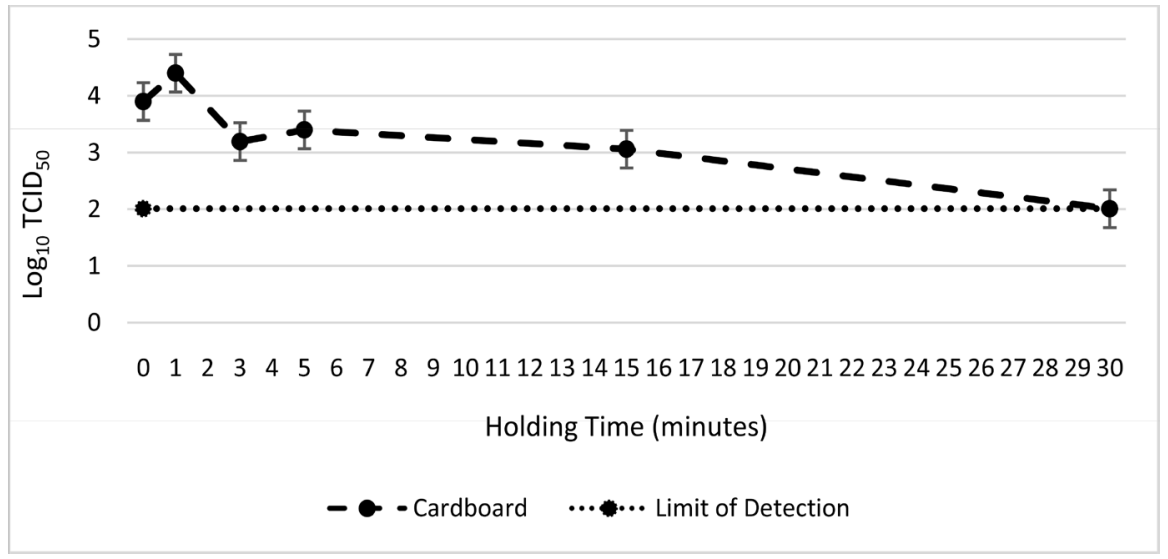

Figure 7. Transferability of SARS-CoV-2 from cardboard to pig skin over 30 minutes (mean \pm standard error).

The amount of SARS-CoV-2 transferred from cardboard to skin over $30 \mathrm{mi}-$ nutes (Figure 7) ranged from $3.90 \log _{10} \mathrm{TCID}_{50}$ per sample at 15 seconds to below the LOD at 30 minutes. In terms of efficiency of transfer, after some relatively efficient transfer from cardboard to skin at 15 seconds and 1 minute $(29 \%$ and $43 \%$ respectively), transfer efficiency quickly decayed to $11 \%$ at 3 minutes, $5.6 \%$ at 5 minutes, and $4.2 \%$ at 15 minutes. At the 30 -minute holding time point for inoculated cardboard, virus was no longer detectable on pig skin, suggesting a transfer efficiency of less than $1.0 \%$, though this value could be as low as zero. In comparison, transfer efficiency ranged from $56 \%$ to $23 \%$ on inoculated plastic mailers during the first 7 hours.

Regression analysis estimates 29.3 minutes (95\% CI 14.1, 120.3) for viral concentrations to reach the LOD for transfer from cardboard. However, even though the point estimate is consistent with the observations at 30 minutes in this study, the heavily biased sample times in the early timeframe (before 15 minutes) and the large width of the confidence interval limit the interpretation of this finding.

\section{Discussion}

The survivability of SARS-CoV-2 on various types of surfaces remains an important factor in evaluating the potential risk of fomite transmission of the virus to potentially cause infection and the disease known as COVID-19. While sparse data are available to compare the findings of the current study, the survivability times determined are similar to those reported by van Doremalen et al. (2020) for cardboard and plastic surfaces [5]. However, the current study is the first study we are aware of to directly evaluate the transfer potential of SARS-CoV-2 to skin from a highly inoculated surface over time and illustrates the importance of considering not only survivability but also transferability, when evaluating material for the potential risk of fomite transmission of SARS-CoV-2.

Our findings indicate that while SARS-CoV-2 may remain viable in cardboard substrates up to 24 hours after inoculation, after only 30 minutes of holding 
time, the transfer of the virus to the skin becomes undetectable. This suggests that cardboard mitigates the potential transfer of the virus to the skin within 30 minutes of inoculation, very significantly reducing or eliminating altogether the potential of becoming ill with COVID-19 from casual contact with a contaminated cardboard package after 30 minutes.

In contrast, the virus remains highly transferable within 7 hours of inoculation of the plastic mailer substrate, with regression analysis predicting that transferability may persist up to 9.5 hours post-inoculation. The risk for fomite transmission of SARS-CoV-2 from plastic mailer substrates is affected by the efficiency of the transfer. In the first 3 hours after inoculation of the substrate, the transfer of the virus from plastic mailers to skin is highly efficient, with measured concentrations on the skin more than half of those measured on the plastic surface. This increases the probability that the concentration of the virus received from this contact by a human receptor could be infective. By comparison, the potential for transfer of the virus from cardboard to skin was decreased by $89 \%$ at 3 minutes, $95 \%$ at 5 minutes and was unmeasurable by 30 minutes. In fact, the potential to transfer virus from cardboard to skin after 3 minutes of holding time was less than that measured for plastic mailers after 7 hours of holding time.

While the mechanism whereby cardboard exhibits a lower transferability of SARS-CoV-2 has not been studied, cardboard is a porous material composed of a cellulose matrix providing substantial binding potential for organic material. A reasonable hypothesis for these findings is that a liquid solution of the virus quickly absorbs into the cellulose matrix of the substrate where the viral particles remain bound until they are no longer viable. This is consistent with other findings that no viable virus could be recovered after 3 hours from printing and tissue papers, even using rigorous laboratory recovery techniques [6]. The high transferability from plastic mailer substrates may be related to the surface feature of the material (smooth and non-porous), resulting in a looser attachment of the viral particles and without permeation of virus into the interior of the material.

There are several strengths to our study. We chose high starting inoculum concentrations of $106.55 \mathrm{TCID}_{50} / \mathrm{mL}$ and $106.43 \mathrm{TCID}_{50} / \mathrm{mL}$, which are approximately an order of magnitude higher than a concentration representative of the higher end of viral concentrations found in the sputum of a human cough. [5] This ensured that viral concentrations would not be underestimated compared to the maximum real-world exposure scenario of a packaging material being exposed to a highly infectious human cough. As well, the use of an organic human skin simulant (pig skin) ensures that a realistic characterization of transfer to skin was achieved as compared to what might be observed with a synthetic material. The manipulation of the skin material on the inoculated substrate (a 5 -second pressing and a swipe) is a novel approach intended to provide a representative model for casual contact with a package.

Selection of material for packaging substrate is an important consideration in 
risk management decision making to control the spread of COVID-19 to consumers, packagers, and carriers. Results suggest that the risk of receiving a potentially infectious concentration of SARS-CoV-2 from contact with a contaminated package is much higher in packages based on a plastic substrate compared to a cardboard substrate, particularly in the first seven hours after contamination occurs. The opportunity to transfer a potentially infectious concentration of SARSCoV-2 from cardboard packaging is mitigated within 30 minutes of holding time, while this risk may persist 7 to 9 hours with a plastic package. Further studies may illustrate the potential effect of the temperature, relative humidity and/or organic matrix on viral survivability and transferability. Future research should also evaluate the generalizability of these results to other respiratory viral pathogens in terms of the differences in fomite transfer potential from packaging substrates to better inform mitigation strategies for infection control.

\section{Acknowledgements}

This work was supported by The Fibre Box Association, a non-profit trade association that represents North American corrugated packaging manufacturers. GTJ, CL, JP, and PW are employed by NCASI, a technical and research nonprofit organization serving the forest products industry.

\section{Conflicts of Interest}

The authors declare no conflicts of interest regarding the publication of this paper.

\section{References}

[1] Centers for Disease Control and Prevention (2020) Interim US Guidance for Risk Assessment and Public Health Management of Persons with Potential Coronavirus Disease 2019 (COVID-19) Exposures: Geographic Risk and Contacts of LaboratoryConfirmed Cases. US Department of Health and Human Services, CDC, Atlanta, USA.

[2] Kampf, G., Todt, D., Pfaender, S. and Steinmann, E. (2020) Persistence of Coronaviruses on Inanimate Surfaces and Their Inactivation with Biocidal Agents. Journal of Hospital Infection, 104, 246-251. https://doi.org/10.1016/j.jhin.2020.01.022

[3] Centers for Disease Control and Prevention. (2020) Situation Summary. US Department of Health and Human Services, CDC, Atlanta, USA.

[4] Centers for Disease Control and Prevention. (2020) Scientific Brief: SARS-CoV-2 and Potential Airborne Transmission. US Department of Health and Human Services, CDC, Atlanta, USA.

[5] van Doremalen, N., Bushmaker, T., Morris, D., Holbrook, M., Gamble, A., Williamson, B., Tamin, A., et al. (2020) Aerosol and Surface Stability of SARS-CoV-2 as Compared with SARS-CoV-1. New England Journal of Medicine, 382, 1564-1567. https://doi.org/10.1056/NEJMc2004973

[6] Chin, A., Chu, J., Perera, M., Hui, K., Yen, H., Chan, M., Peiris, M., et al. (2020) Stability of SARS-CoV-2 in Different Environmental Conditions. Lancet Microbe, 1, Article No. E10. https://doi.org/10.1016/S2666-5247(20)30003-3 
[7] Brady, T., Strauch, A., Almaguer, C., Niezgoda, G., Shaffer, R., Yorio, P. and Fisher, E. (2017) Transfer of Bacteriophage MS2 and Fluorescein from N95 Filtering Facepiece Respirators to Hands: Measuring Fomite Potential. Journal of Occupational and Environmental Hygiene, 14, 898-906. https://doi.org/10.1080/15459624.2017.1346799

[8] Julian, T.R., Leckie, J.O. and Boehm, A.B. (2010) Virus Transfer between Fingerpads and Fomites. Journal of Applied Microbiology, 109, 1868-1874. https://doi.org/10.1111/j.1365-2672.2010.04814.x

[9] Kraay, A., Hayashi, M., Hernandez-Ceron, N., Spicknall, I., Eisenberg, M., Meza, R. and Eisenberg, J. (2018) Fomite-Mediated Transmission as a Sufficient Pathway: A Comparative Analysis across Three Viral Pathogens. BMC Infectious Diseases, 18, 540. https://doi.org/10.1186/s12879-018-3425-x

[10] Kärber, G. (1931) Beitrag zur kollektiven Behandlung pharmakologischer Reihenversuche. Naunyn-Schmiedebergs Archiv für experimentelle Pathologie und Pharmakologie, 162, 480-483. https://doi.org/10.1007/BF01863914

[11] Spearman, C. (1908) The Method of "Right and Wrong Cases" (Constant Stimuli) without Gauss's Formula. British Journal of Psychology, 2, 227-242. https://doi.org/10.1111/j.2044-8295.1908.tb00176.x

[12] Enders, J.F. (1954) Cytopathology of Virus Infections. Annual Review of Microbiology, 8, 473-502. https://doi.org/10.1146/annurev.mi.08.100154.002353

\section{Appendix 1: Tabulated Results of Survivability and Transferability Experiments.}

Table 1 . The results of survivability and transferability of SARS-CoV-2 on cardboard packaging substrates.

\begin{tabular}{cccccccc}
\hline \multirow{2}{*}{ Sample } & \multicolumn{7}{c}{ Viral units $\left(\log _{10} \operatorname{TCID}_{50}\right)^{* *}$ per sample } \\
\cline { 2 - 7 } & $\mathbf{1 5 ~ s}$ & $\mathbf{1} \mathbf{~ m i n}$ & $\mathbf{3} \mathbf{m i n}$ & $\mathbf{5} \mathbf{m i n}$ & $\mathbf{1 5} \mathbf{m i n}$ & $\mathbf{3 0} \mathbf{m i n}$ & $\mathbf{6 0} \mathbf{~ m i n}$ \\
\hline Cardboard-survivability* & $4.44(0.07)$ & $4.77(0.32)$ & $4.15(0.07)$ & $4.65(0.07)$ & $4.44(0.19)$ & $4.02(0.26)$ & $4.02(0.08)$ \\
Cardboard-transferability* & $3.90(0.47)$ & $4.40(0.19)$ & $3.19(0.14)$ & $3.40(0.19)$ & $3.06(0.09)$ & $<2.01(0.00)$ & $<1.93(0.14)$ \\
\hline
\end{tabular}

${ }^{\star}$ Virus extracted by rigorous scraping; ${ }^{*}$ Expressed asthe average (standard deviation) of three experiments

Table 2. The results of survivability and transferability of SARS-CoV-2 on plastic packaging substrates.

\begin{tabular}{cccccccc}
\hline \multirow{2}{*}{ Sample } & \multicolumn{7}{c}{ Viral units $\left(\log _{10} \mathrm{TCID}_{50}\right)^{* *}$ per sample } \\
\cline { 2 - 7 } & $\mathbf{1 ~ h r}$ & $\mathbf{3 ~ h r}$ & $\mathbf{7 ~ h r}$ & $\mathbf{1 2} \mathbf{h r}$ & $\mathbf{1 6} \mathbf{h r}$ & $\mathbf{3 6 ~ h r}$ \\
\hline Plastic-survivability & $4.57(0.19)$ & $4.23(0.13)$ & $3.32(0.19)$ & $3.23(0.00)$ & $2.79(0.17)$ & $<1.93(0.13)$ \\
Plastic-transferability & $4.32(0.08)$ & $3.98(0.33)$ & $2.68(0.34)$ & $<1.93(0.14)$ & $<2.07(0.05)$ & $<2.01(0.00)$ \\
\hline
\end{tabular}

${ }^{\star}$ Virus extracted by rigorous scraping; ${ }^{*}$ Expressed as the average (standard deviation) of three experiments 